\title{
Effect of exposure on salmon lice Lepeophtheirus salmonis population dynamics in Faroese salmon farms
}

\author{
Esbern J. Patursson ${ }^{1,2, *}$, Knud Simonsen ${ }^{1}$, André W. Visser ${ }^{2}$, Øystein Patursson ${ }^{1}$ \\ ${ }^{1}$ Fiskaaling - Aquaculture Research Station of the Faroes, við Áir, 430 Hvalvík, Faroe Islands \\ ${ }^{2}$ VKR Centre for Ocean Life, National Institute of Aquatic Resources, Technical University of Denmark, Kavalergaarden 6, \\ 2920 Charlottenlund, Denmark
}

\begin{abstract}
We assessed variations in salmon lice Lepeophtheirus salmonis population dynamics in Faroese salmon farms in relationship to their physical exposure to local circulation patterns and flushing with adjacent waters. Factors used in this study to quantify physical exposure are estimates of the freshwater exchange rate, the tidal exchange rate and dispersion by tidal currents. Salmon farms were ranked according to the rate of increase in the average numbers of salmon lice per fish. In a multiple linear regression, physical exposure together with temperature were shown to have a significant effect on the rate of lice infection. The sites with low exposure revealed higher rates of self-infection and internally driven outbreak dynamics, while high-exposure sites showed lower rates of self-infection, tending towards externally driven outbreak dynamics. The lowexposure sites also appeared to have a lower threshold of salmon stocking numbers for outbreaks of infection. The study presents a simple method of characterizing salmon farming fjords in terms of their different exposure levels and how they relate to potential self-infection at these sites.
\end{abstract}

KEY WORDS: Sea lice $\cdot$ Fjord $\cdot$ Freshwater exchange $\cdot$ Tidal exchange $\cdot$ Tidal currents $\cdot$ Salmo salar . Self-infection $\cdot$ Faroe Islands

\section{INTRODUCTION}

Stocking hundreds of thousands of fish in small areas makes fish farms ideal breeding grounds for sea lice (including salmon lice Lepeophtheirus salmonis [Krøyer, 1837]). The lice feed on the protective slime layer, the scales and blood of the salmon, and thereby impair the salmon immune system, reduce its ability to osmo-regulate and cause stress (Pike \& Wadsworth 1999). The Faroe Islands require by law that the number of sea lice are monitored in the farming industry (Faroese Food and Veterinary Authority $2009,2013)$. The total yearly cost of the sea lice is estimated to $€ 0.19 \mathrm{~kg}^{-1}$ fish (Costello 2009), which totals over $€ 15$ million for the production of $82000 \mathrm{t}$ in 2015 in the Faroe Islands alone. High costs,

\footnotetext{
${ }^{*}$ Corresponding author: esbern_p@hotmail.com
}

environmental concerns and increased resistance to pharmaceutical treatments (Jimenez et al. 2011) in this rapidly expanding industry provide a strong incentive to develop effective and sustainable methods for the control of sea lice.

Outbreaks of sea lice infections vary considerably between sites. Some farms regularly experience severe sea lice epidemics, while others are barely affected. The reason for such variation is complex, but includes animal husbandry practices such as disease management procedures as well as the physical and biological conditions of the particular location. For example, flushing with adjacent waters may reduce reinfection rates (Pike \& Wadsworth 1999).

The life cycle of the salmon louse $L$. salmonis is composed of multiple stages, including 2 planktonic

() The authors 2017. Open Access under Creative Commons by Attribution Licence. Use, distribution and reproduction are unrestricted. Authors and original publication must be credited. 
stages (nauplius I and II) that are followed by a free-swimming infectious copepodid stage, which is mainly restricted to the upper layers of the sea (Hevrøy et al. 2003). Once attached to a host, copepodids eventually develop into adults, and adult females potentially release 26 to 68 nauplii through the protruding egg sacs daily, which then are free to develop to the copepodid stage and to infect other hosts (Heuch et al. 2000, á Norði et al. 2016). The growth of a sea lice population has an exponential nature (Frazer et al. 2012) and is generally modelled as such (Costello 2006, Krkošek et al. 2010, Frazer et al. 2012). Several dispersion models have been developed which assume that the planktonic stages of the sea lice drift freely with prevailing currents close to the surface (Amundrud \& Murray 2009, Adams et al. 2012, Salama et al. 2013, Asplin et al. 2014), with recent works including vertical positioning as a response to environmental cues (Johnsen et al. 2014, 2016). Sea temperature is widely accepted as a basic factor influencing the growth rate of sea lice populations, as the generation time decreases with increasing temperature (Tully 1992, Heuch et al. 2000). However, the relationship between temperature and the sea lice abundance is not a simple relationship, and annual peaks and troughs in the abundance of mobile L. salmonis may appear delayed compared with maximum and minimum annual temperature (Jansen et al. 2012). Naupliar development is salinity dependent, and complete development from nauplii to copepodid is only achieved at salinities $\geq 30 \%$ (Pike \& Wadsworth 1999, Brooks 2005). The copepodid has a slightly greater survival rate at lowered salinities than the nauplii, but survives best above 15\% (Pike \& Wadsworth 1999). Other authors have stated that $L$. salmonis tend to avoid salinities below 24-25\%o (Krkošek et al. 2005, Asplin et al. 2014). A key concept in theoretical epidemiology is that increasing host density should promote the population growth of a parasite as the chance of contact increases with increased host density (Anderson \& May 1991). High abundances of fish, not only within individual farms but also integrated across farming regions, can affect sea lice outbreaks. Thus, the negative feedback from high densities is not solely due to the density of fish at each site or pen, but also to the density in farming regions (Jansen et al. 2012).

High L. salmonis abundance and potential reinfection is often associated with farms situated in areas with weak exchange of waters (Tully \& Nolan 2002, Revie et al. 2003). Krkošek et al. (2010) introduced a salmon lice growth model based on simple mathematical host-macroparasite models following the Anderson-May approach (Anderson \& May 1978). Growth is split into 2 modes. One is the externally driven mode, which assumes that copepodids enter the farm from the external environment and nauplii released from adult sea lice disperse into the external environment with no re-infection of farmed fish. The other mode is internally driven, and assumes that re-infection and population dynamics are driven from the parasite population inside the farm or the local environment. The internally driven mode will have an exponential salmon lice population growth, whereas the externally driven model will have a constant growth rate reaching a steadystate when the infection pressure equals mortality.

There are 3 basic processes that induce circulation in an estuary: wind, tides and the density-driven flow associated with freshwater inflow (Pritchard 1967). Tides are mainly manifested as oscillatory currents, but also produce residual eddies that can effect a net exchange through inlets (Visser \& Bowman 1991), and exchange of suspended material (e.g. planktonic organisms) by tidal dispersion (Geyer \& Signell 1992, Nguyen et al. 2008). In the Faroe Islands, the tidal currents are quite moderate in most fjords hosting the majority of the fish farms, but relatively strong with maximum speeds up to 7 knots in the straits between the islands (Simonsen \& Niclasen 2011).

Together with temperature and host density, sea lice population dynamics in various Faroese fish farming fjords may be expected to vary in accordance with the flushing rate of these fjords with adjacent waters. The principle factors involved in this exchange of waters are the tidal range, tidal dispersion and freshwater forcing, which we combine and refer to herein as the 'exposure' of a fjord. Even though winds are also a strong influence on the exchange of water in the fjords, they tend to be highly variable in strength and direction. Their net effect on the water exchange is not easily quantified, and thus is not included in present study. We also exclude the effects of salinity. Even though sea lice prefer high salinities (Pike \& Wadsworth 1999, Brooks 2005, Krkošek et al. 2005, Asplin et al. 2014), the salinity in the typical Faroese fjord is nowhere near the threshold for any observable impact. The salinity in the Faroe shelf ranges from 35.1 to $35.3 \%$ o (Hansen \& Østerhus 2000, Larsen et al. 2008), and the salinity in the fjords is only slightly lower (Gaard et al. 2011).

Observations of sea lice dynamics are obtained from the compulsory sea lice monitoring programme (Faroese Food and Veterinary Authority 2009, 2013). These observations are a valuable resource, lending much needed insight into the epidemiology of sea lice 
infections (Pike \& Wadsworth 1999), not only in their inherent dynamics, but also how self-infection can be influenced by the physical exposure of farming sites.

\section{MATERIALS AND METHODS}

\section{Study area}

The waters around the Faroe Islands are dominated by the relatively warm and saline North Atlantic Current Water, a derivative of the Gulf Stream. On the shelf is a steady current clockwise around the islands, partly driven by tidal rectification (Larsen et al. 2008), i.e. a mean current generated by the nonlinearities inherent in tidal dynamics and strongly influenced by bathymetry. The tidal wave enters the southwestern shelf and propagates on both sides of the archipelago to be rejoined on the northeastern shelf, with a virtual amphidromic point for the dominant semidiurnal tides on the eastern coast on the central island. This causes strong tidal currents in the straits between the islands (Simonsen \& Niclasen 2011). In contrast, tidal currents within fjords tend to be much weaker, decreasing in intensity with distance from the open sea. Tidal currents and wave action induce intense mixing on the shelf and produce a very homogenous water mass, with temperature varying around $12^{\circ} \mathrm{C}$ in summer to slightly below $6^{\circ} \mathrm{C}$ in winter, and salinity from about 35 to $35.3 \%$ (Larsen et al. 2008, Gaard et al. 2011). The fjords are slightly fresher due to the runoff from land, with some stratification. The salinity in the upper layers of Faroese fjords usually ranges between 34.5 and $34.9 \%$ in summer and between 33.6 and $34.8 \%$ in winter (Gaard et al. 2011). Most of the fjords in the Faroe Islands are simple systems, with usually 1 or 2 aquaculture sites in each fjord (Fig. 1) compared, for example, to the larger and more complex fjord systems seen in Norway. The homogeneity of the water in the fjords (Larsen et al. 2008, Gaard et al. 2011), the negligible effect of salinity, the simplicity of the fjord systems and the high variation in exposure make the Faroe Islands ideal for studying the effect of physical exposure on salmon lice population dynamics.

\section{Sea lice data}

Sea lice data were obtained from the Fiskaaling Aquaculture Research Station (ARSF) of the Faroes, with permission from the farming companies in the
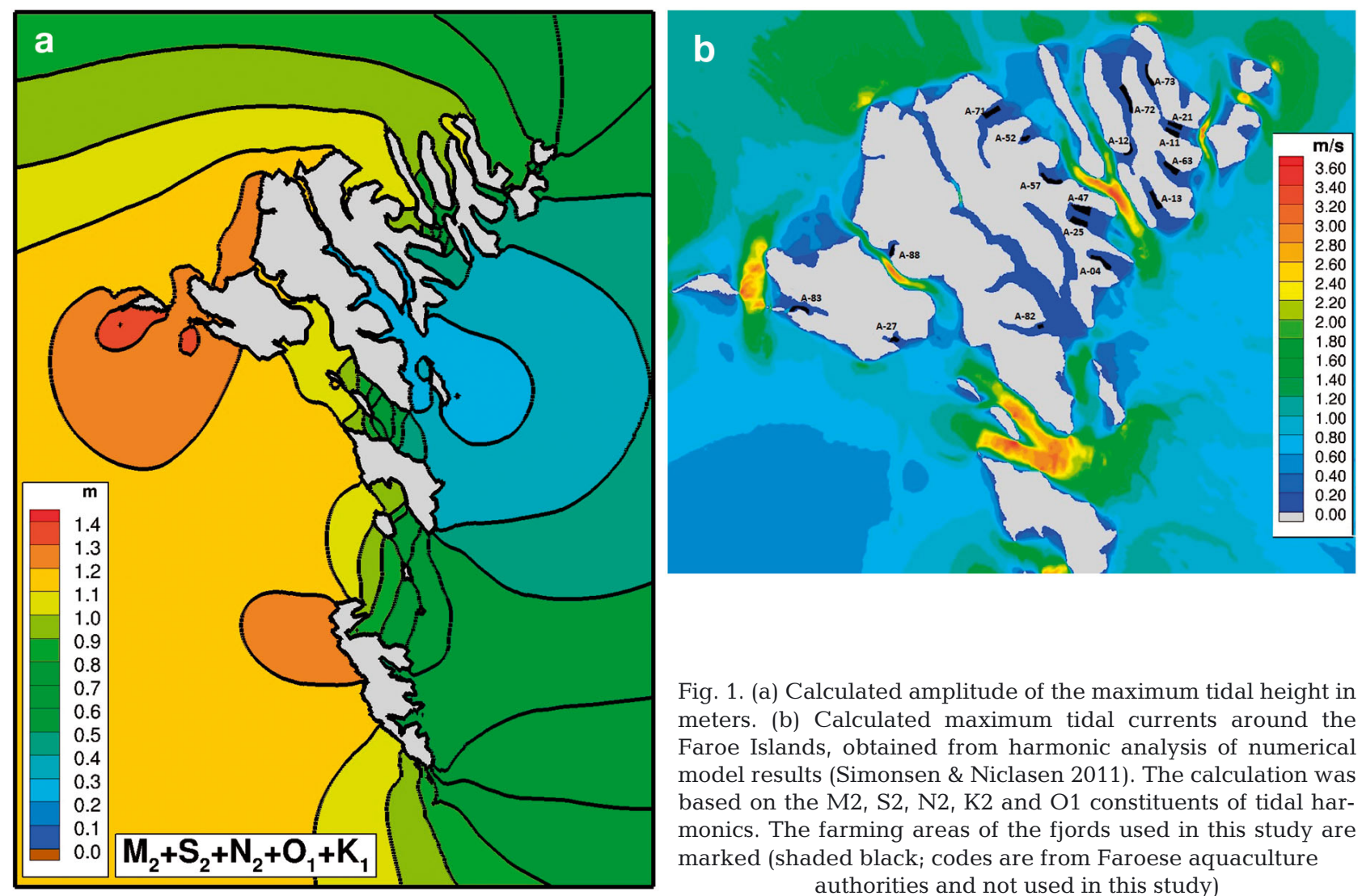

Fig. 1. (a) Calculated amplitude of the maximum tidal height in meters. (b) Calculated maximum tidal currents around the Faroe Islands, obtained from harmonic analysis of numerical model results (Simonsen \& Niclasen 2011). The calculation was based on the M2, S2, N2, K2 and O1 constituents of tidal harmonics. The farming areas of the fjords used in this study are marked (shaded black; codes are from Faroese aquaculture authorities and not used in this study) 
Faroe Islands. A team at ARSF conducts the monitoring on behalf of the farmers, ensuring standardized monitoring practices. The minimum legal requirement (Faroese Food and Veterinary Authority 2009, 2013), is that 2 fixed and 2 random pens are monitored for sea lice at each site. Here the average numbers of salmon lice (motile Lepeophtheirus salmonis) in the 2 fixed pens were used. Non-motile stages (chalimus) were not included, as there is no distinction between L. salmonis and Caligus elongatus in the monitoring programme. In a few cases, only data from a single pen was available. To avoid the problem of routine treatment and differences in these treatments (Jaworski \& Holm 1992), we only used data collected before any treatment was implemented on the farm.

\section{Temperature, freshwater and tidal data}

Temperature data were obtained from a measuring station representing the well-mixed shelf water (Larsen et al. 2008). The temperature in the fjords, particularly at the surface, may vary slightly from the shelf temperature, but generally this variation is less than $1^{\circ} \mathrm{C}$ (Larsen et al. 2008, Gaard et al. 2011).

The average precipitation per unit area over the Faroe Islands was obtained by the isohyet map of Davidsen et al. (1994), which was combined with a topographic map available from an internet map service (www.kortal.fo) to obtain the catchment area and thus average runoff into each fjord.

Tidal data were from a numerical simulation with a barotrophic version of the regional oceanic modeling system (ROMS) (Shchepetkin \& McWilliams 2005) set up for the Faroe Shelf with 100 m equidistant resolution. The currents were validated against vertically averaged current profile data in 4 channels and on the western shelf, while sea surface elevation was validated against 21 tidal gauge stations around the islands (Simonsen \& Niclasen 2011). The maximum tidal range for the entire shelf is calculated from the amplitudes of the $\mathrm{M}_{2}, \mathrm{~S}_{2}, \mathrm{~N}_{2}, \mathrm{O}_{1}$ and $\mathrm{K}_{1}$ constituents. The calculated maximum tidal range $(H)$ reaches its maximum at $2.8 \mathrm{~m}$ at the western islands, and decreases to a minimum of $0.4 \mathrm{~m}$ east of the central island (Fig. 1). The minimum amplitudes of the dominating $\mathrm{M}_{2}$ and $\mathrm{S}_{2}$ constituents are 0.14 and 0.056 , respectively (Farvandsvæesenet 2005). The fjords are therefore all microtidal to mesotidal (Mikhailov 1997).

A theoretical maximum current estimate $(U)$ was estimated as the sum of the semi major axes of the $\mathrm{M}_{2}, \mathrm{~S}_{2}, \mathrm{~N}_{2}, \mathrm{O}_{1}, \mathrm{~K}_{1}$ and $\mathrm{Q}_{1}$, respectively. The highest values of $U$ in the straits exceed $3.5 \mathrm{~m} \mathrm{~s}^{-1}$ (Fig. 1b). The simulation underestimates the current near land and in the fjords, but is fairly representative in the straits (Simonsen \& Niclasen 2011).

\section{Exchange rates}

The freshwater exchange rate $\left(E_{\mathrm{f}} ; \mathrm{d}^{-1}\right)$ is defined as the ratio between the average daily freshwater runoff $(R)$ and the volume of the fjord $\left(V_{\mathrm{f}}\right)$ :

$$
E_{\mathrm{f}}=\frac{R}{V_{\mathrm{f}}}
$$

The tidal prism $(P)$ is the area of the fjord $(A)$ multiplied by the tidal range $(H)$ :

$$
P=H \times A
$$

The tidal exchange rate $\left(E_{\mathrm{t}} ; \mathrm{d}^{-1}\right)$ is the tidal prism $(P)$ divided by the volume of the fjord $\left(V_{\mathrm{f}}\right)$, divided by the tidal period $(t)$; this may be written as:

$$
E_{\mathrm{t}}=P / V_{\mathrm{f}} \times t=H / D \times t
$$

where $D$ is the average depth of the fjord.

Energetic currents outside the fjord may drive residual eddies in the fjord, and effect an exchange of waters through tidal dispersion (Geyer \& Signell 1992, Nguyen et al. 2008). Several eddies may appear from the mouth to the head of the fjord, where the outermost eddies are the most energetic and the strength decreases with the distance from the fjord mouth. The size and strength of the eddies may be related to the width $(W)$ of the mouth (Nguyen et al. 2008). An estimate of the tidal dispersion effect $\left(E_{\text {tp }}\right)$ at a fish farm at a distance $\left(L_{1}\right)$ from the mouth of the fjord is estimated by the tidal excursion scaled by the ratio of $W$ to the distance $\left(L_{2}\right)$ to the fjord mouth (Fig. 2), i.e.

$$
E_{t p}=\frac{U \times t}{L_{1}+L_{2}} \times \frac{W}{L_{1}}
$$

where $U$ is the maximum current speed outside the fjord, $t$ is the tidal period, and $L_{2}$ is length from the mouth of the fjord to the maximum measured current speed outside the fjord.

\section{Salmon lice population dynamics}

Examples of the population growth of the salmon lice are shown in Fig. 3. These show the average number of L. salmonis (both motile + adult L. salmonis) per fish at selected sites. The rate of increase $(S)$, estimated from the slope of the corresponding loglinear plot (Fig. 3) was used as the response variable 


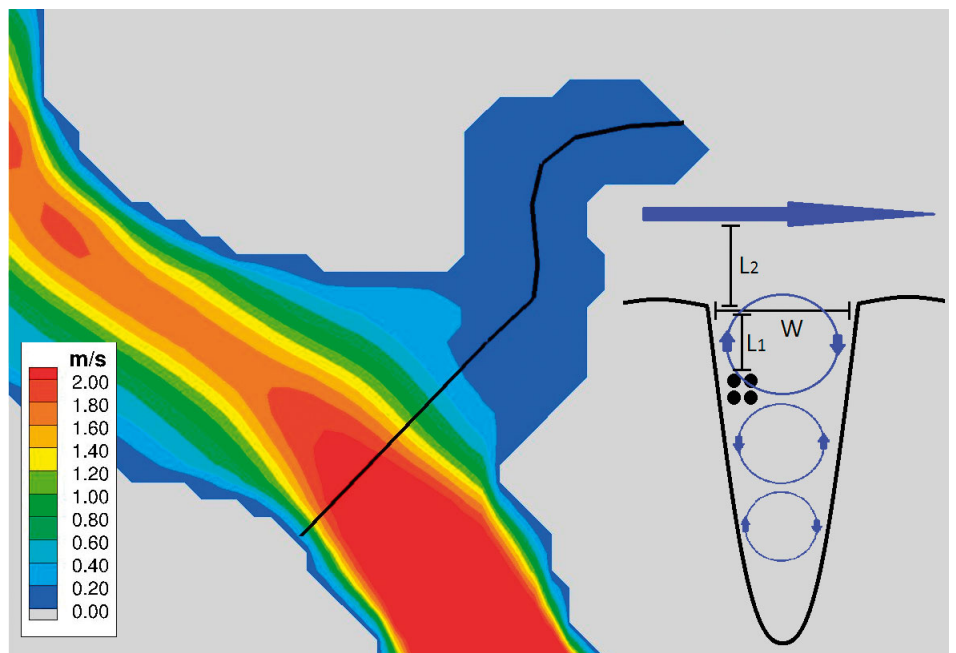

Fig. 2. Enlargement of the calculated maximum tidal currents (color coded $\mathrm{m} \mathrm{s}^{-1}$ ) in a single fjord, with a sketch of the tidal dispersion effect with regards to residual eddies (blue circles). The large arrow at the top of the sketch represents the maximum current measured in the channel. The location of the farm is shown as 4 small circles at the left of the fjord, with distance $L_{1}$ from the mouth of the fjord. The other length scales used in the calculations are $W$ (width of the fjord at its mouth) and $L_{2}$ (distance from the mouth to the maximum current). Distances are measured along the centerline of the fjord (black line)

in the statistical analysis. We selected only periods where the data showed a clear exponential growth, as illustrated in Fig. 3, to avoid long periods at the start of the monitoring data with no lice, or small outbreaks, which would decrease the slope significantly.

\section{Temperature and host density}

In order to isolate the effect of exposure on the growth rate, the effect of temperature $(T)$ can be removed by de-trending the slope with respect to temperature, as shown in Fig. 4.
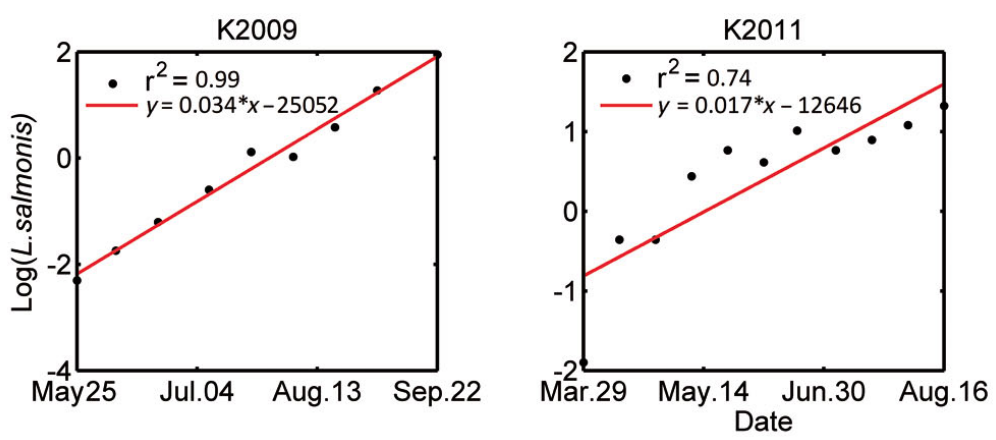

\section{RESULTS}

The population growth rates $S_{\mathrm{t}}$ are listed in Table 1, and vary between 0.01 and 0.034 (lice fish ${ }^{-1} \mathrm{~d}^{-1}$ ), and the linear model that best relates these to exposure factors (Eq. 5) is given by the following formula:

Host density was quantified as the total number of stocked salmon in the fjord at the time of salmon lice monitoring. However, as this measure did not seem to have a significant effect in the statistical analysis, it was not included.

\section{Statistical analysis}

A multiple linear regression was used to examine the effect of exposure on the salmon lice population dynamics. Based on the theory that self-infecting growth follows an exponential trend (Krkošek et al. 2010), we tested the hypothesis that there is a lower rate of self-infection at the more exposed sites. The final analysis of the effect of exposure on salmon lice population dynamics was investigated by a multiple linear regression of the exposure factors $E_{\mathrm{tp}}, E_{\mathrm{f}}$ and $E_{\mathrm{t}}$ on the temperature de-trended slopes $\left(S_{t}\right)$ (Fig. 5):

$$
S_{\mathrm{t}}=\beta_{0}+\beta_{1} E_{\mathrm{tp}}+\beta_{2} E_{\mathrm{f}}+\beta_{3} E_{\mathrm{t}}+\varepsilon
$$

The multiple linear regression was used to determine whether the predictor variables have a significant effect on $S_{\mathrm{t}}$, and to get estimates of the $\beta$ values to determine their proportional explanatory values. All statistical analyses were made using the software $\mathrm{R}$ ( $\mathrm{R}$ Core Team 2013).

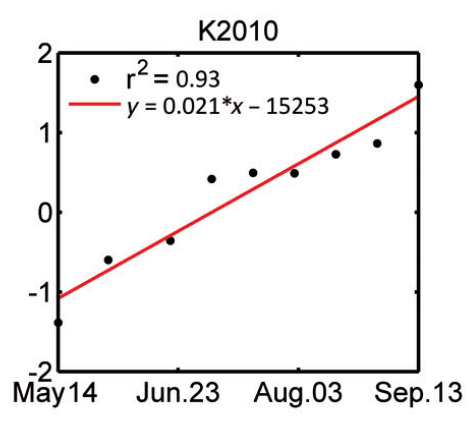

Fig. 3. Log of salmon lice Lepeophtheirus salmonis population growth (salmon lice per fish) over time in data sets K2009, K2010 and K2011 (identified by the letter of the fjord and the year of the grow-out phase), and the calculated slopes obtained from the red trend lines using a linear curvefit in Matlab 


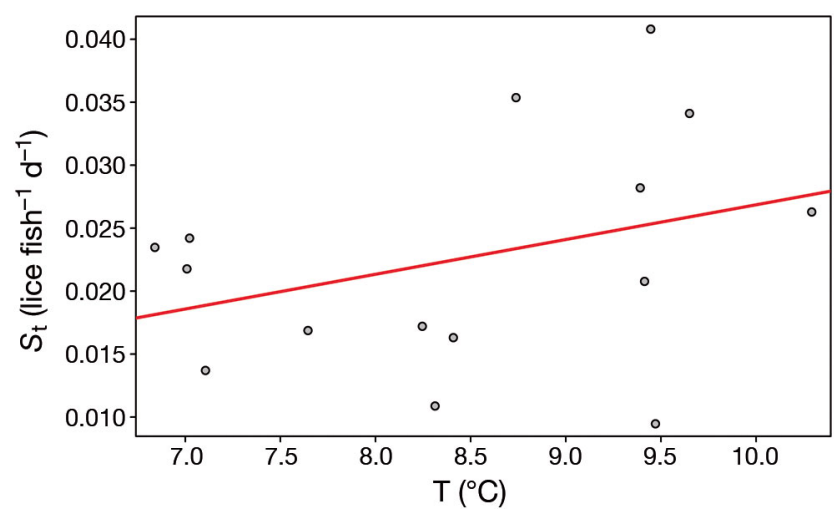

Fig. 4. Correlation between average water temperature (T) in the sampled Faroese fjords and population growth rates $\left(S_{t}\right)$ of salmon lice Lepeophtheirus salmonis

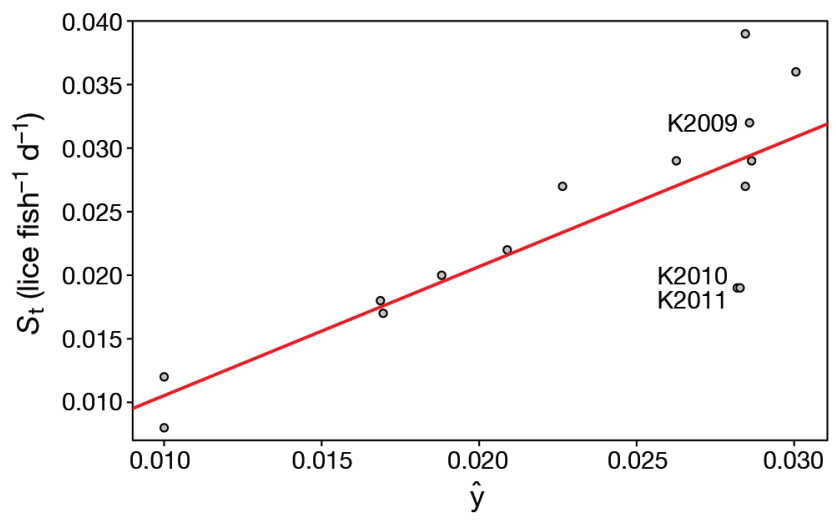

Fig. 5. Observed population growth rate $\left(S_{\mathrm{t}}\right)$ of salmon lice Lepeophtheirus salmonis and that predicted by exposure effects ( $\hat{y}$, Eq. 6). K2009, K2010 and K2011 refer to the different data sets used (identified by the letter of the fjord and the year of the grow-out phase)

$$
\hat{\mathrm{Y}}=0.0343-0.000435 E_{\mathrm{tp}}-9.36 E_{\mathrm{f}}-0.00895 E_{\mathrm{t}}
$$

and is illustrated in Fig. 5. The joint F-test for the model was significant $(\mathrm{p}<0.01)$.

The regression coefficients were all negative, indicating that higher exposure factors (i.e. greater tidal exchange, greater freshwater forcing and greater dispersion) resulted in a lower growth rate of salmon lice. Some of these factors were more significant than others. Tidal dispersion $\left(E_{\mathrm{tp}}\right)$ showed greater significance $(\mathrm{p}=0.028)$ than either freshwater forcing $\left(E_{\mathrm{f}}\right)$ or the tidal exchange $\left(E_{\mathrm{t}}\right)(\mathrm{p}=0.17$ and $\mathrm{p}=0.87$, respectively). This was likely due to the multicollinearity of these factors. However, if either $E_{\mathrm{f}}$ or $E_{\mathrm{t}}$ were removed from the regression, the other was significant, and including both gave the best model fit. The $\mathrm{r}^{2}$ value of the model was 0.65 , meaning that $65 \%$ of the variation in $S_{\mathrm{t}}$ can be explained by the exposure variables.
Table 1. Monitoring data sets, identified by a letter for the fjord and the year of the grow-out phase, with exponential growth curves of salmon lice Lepeophtheirus salmonis. Fjord D had 2 farms in 2010.The slopes of the salmon lice growth curves $\left(S_{\mathrm{t}}\right.$, lice fish $\left.{ }^{-1} \mathrm{~d}^{-1}\right), \mathrm{r}^{2}$ values of the fitted growth lines and the standard errors (SE) for the slopes and the calculated values of the exposure factors $E_{\mathrm{f}}$ (freshwater exchange rate, $\left.\mathrm{d}^{-1}\right), E_{\mathrm{t}}$ (tidal exchange rate, $\mathrm{d}^{-1}$ ) and $E_{\text {tp }}$ (tidal dispersion) (Eqs. 1-4) are given

\begin{tabular}{|lcccccc|}
\hline Data set & $S_{\mathrm{t}}$ & $\mathrm{r}^{2}$ & $\mathrm{SE}$ & $E_{\mathrm{f}}$ & $E_{\mathrm{t}}$ & $E_{\mathrm{tp}}$ \\
\hline G2011 & 0.026 & 0.92 & 0.005 & 0.00076 & 0.2 & 10.42 \\
B2010 & 0.009 & 0.77 & 0.003 & 0.00172 & 0.19 & 15.05 \\
B2012 & 0.011 & 0.72 & 0.004 & 0.00172 & 0.19 & 15.05 \\
N2010 & 0.035 & 0.86 & 0.022 & 0.00021 & 0.03 & 4.52 \\
J2009 & 0.041 & 0.99 & 0.003 & 0.00042 & 0.04 & 3.53 \\
J2011 & 0.022 & 0.95 & 0.003 & 0.00042 & 0.04 & 3.53 \\
L2011 & 0.024 & 0.87 & 0.004 & 0.00035 & 0.05 & 4.51 \\
K2009 & 0.034 & 0.99 & 0.002 & 0.00026 & 0.04 & 6.7 \\
K2010 & 0.021 & 0.93 & 0.003 & 0.00026 & 0.04 & 7.58 \\
K2011 & 0.017 & 0.74 & 0.004 & 0.00026 & 0.04 & 7.38 \\
I2009 & 0.023 & 0.80 & 0.011 & 0.00051 & 0.08 & 6.06 \\
D2010_2 & 0.028 & 0.93 & 0.004 & 0.00027 & 0.05 & 19.8 \\
D2010_1 & 0.016 & 0.96 & 0.002 & 0.00027 & 0.05 & 32.89 \\
C2011 & 0.014 & 0.86 & 0.003 & 0.00063 & 0.09 & 24.7 \\
E2010 & 0.017 & 0.93 & 0.004 & 0.00048 & 0.09 & 23.59 \\
\hline
\end{tabular}

The exposure was calculated for all fjords (Fig. 6), including those that did not show exponential growth, or had insufficient data (e.g. due to early implementation of treatments, high Caligus elongatus contamination, movement of the farms to different locations). Exposure was estimated according to the best fit regression coefficients:

Exposure $=0.000435 E_{\mathrm{tp}}+9.36 E_{\mathrm{f}}+0.00895 E_{\mathrm{t}}$

The exposure of fjord A lies outside the range in the model. Therefore, the exposure and the proportional values of the estimated predictor variables of

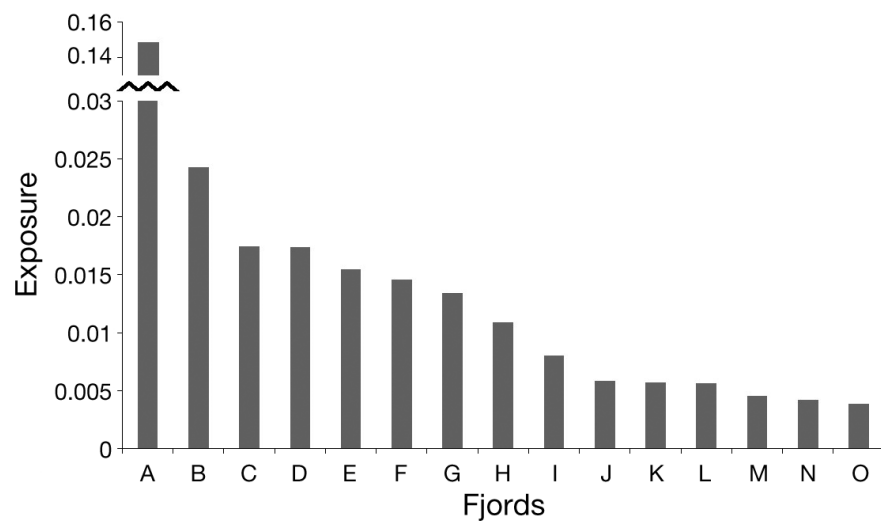

Fig. 6. Estimated exposure for all sampled fjords (Eq. 7). Note the exposure for fjord $\mathrm{A}$ is an order of magnitude higher than for the other fjords 


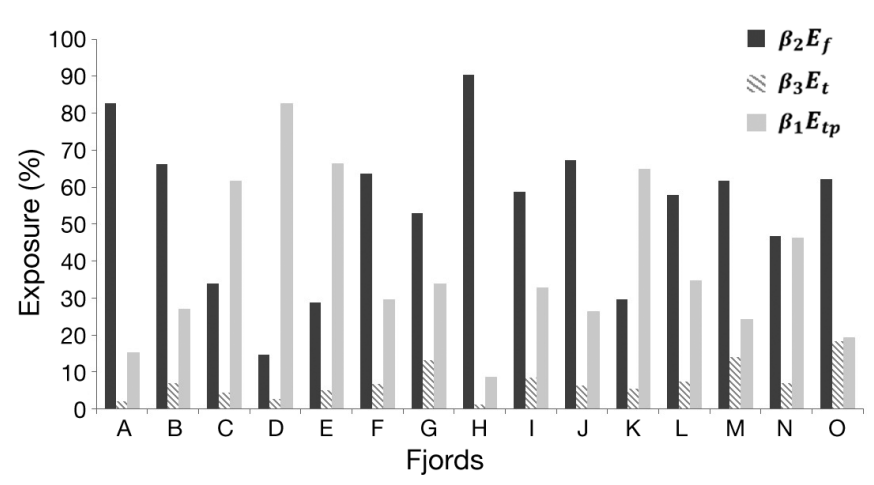

Fig. 7. Percentage of exposure (Eq. 7) explained by each weighed variable, viz. the freshwater exchange rate $\left(\beta_{2} E_{\mathrm{f}}\right)$, the tidal exchange rate $\left(\beta_{3} E_{\mathrm{t}}\right)$ and the tidal dispersion $\left(\beta_{1} E_{\mathrm{tp}}\right)$, for all sampled fjords

fjord A are questionable. However, as A has by far the highest values in all exchange rates, it is safe to assume that the level of exposure is highest in this fjord. The relative explanatory values of the exposure factors for all sites are estimated in Fig. 7.

\section{DISCUSSION}

We have demonstrated that the physical exposure of a salmon farm site has a highly significant effect on the salmon lice population dynamics, where a higher exposure corresponds to a lower rate of self-infection and vice versa. We have characterized exposure level in terms of relatively easily accessible parameters (tidal range, tidal currents, freshwater inflow), for which we can mechanistically describe a direct influence $\left(E_{\mathrm{f}}, E_{\mathrm{t}}\right.$ and $\left.E_{\mathrm{tp}}\right)$ on the flushing of water at a farm location.

Nearly all of the salmon farms examined displayed exponential growth of salmon lice, and therefore internally driven population dynamics (Krkošek et al. 2010). The only clear exception was fjord A, which exhibited externally driven outbreak dynamics (Fig. 8), reaching a relatively uniform level of infection after a rapid growth phase. Fjord B exhibited somewhat of a mixture of internally and externally driven outbreak dynamics (Fig. 8). While fits to an exponential model were significant (Table 1 ), the infection rates make it difficult to distinguish between exponential and linear growth. These 2 sites displaying signs of externally driven outbreak dynamics were also the most exposed sites (Fig. 6).

The sea temperature on the shelf was used as a reference for the temperature in all sampled fjords and should be a good estimation, as the temperature around the islands is spatially homogenous (Larsen et al. 2008). Including the average sea temperature in the multiple linear regression gave a significant effect on the slope depending on time of year. However, as the aim was to investigate the effect of exposure on salmon lice population dynamics, the temperature effect was removed by de-trending the growth rates.

Both the number and size of salmon in a given area are potentially important parameters in driving the dynamics of sea lice infections. The greater the density of hosts, the more severe an outbreak (Anderson \& May 1991). Likewise, large hosts can carry a greater number of parasites (Lees et al. 2008, Heuch et al. 2009, Jansen et al. 2012), increasing contact rates and exposure time (Jackson \& Minchin 1992, Tucker et al. 2002). The complexity of host density on sea lice population dynamics is further increased by 'the dilution effect', a negative relationship between host density and infection intensity (Samsing et al. 2014).

We could not find any significant relationship between the total number of salmon in a fjord and infection rate. However, there is an indication that the exposure level of fjords influences the stocking
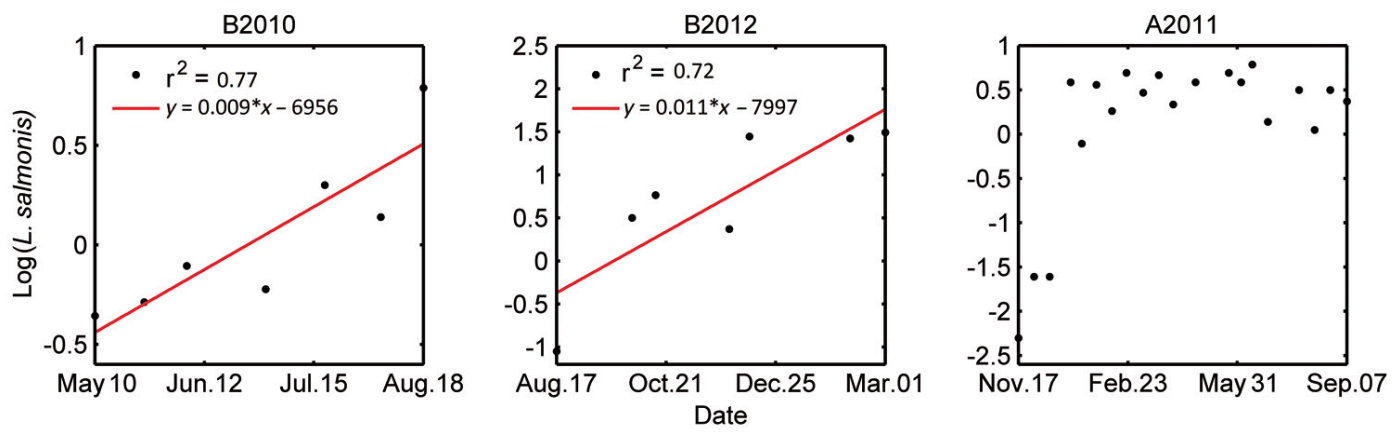

Fig. 8. Log of salmon lice Lepeophtheirus salmonis population growth (salmon lice per fish) over time in data sets B2010, B2012 and A2011 (identified by the letter of the fjord and the year of the grow-out phase), and the calculated slopes obtained from the red trend lines 


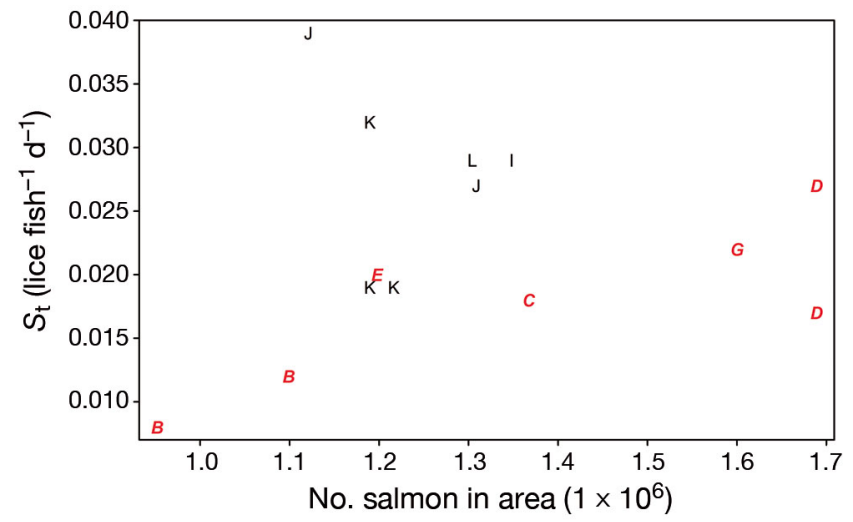

Fig. 9. Correlation between the slopes of the salmon lice Lepeophtheirus salmonis growth curves $S_{\mathrm{t}}$ and the total number of stocked Atlantic salmon Salmo salar in the sampled fjords in millions. The fjords with the lowest exposure $(<0.01)$ are marked in red italics, and the higher-exposure fjords (>0.01) are shown in normal font

density threshold at which outbreaks occur (Fig. 9). Specifically, at low-exposure sites, the infection rate tends to increase faster with the total number of salmon than at high-exposure sites. One final point to note is that current speed can strongly influence the attachment of sea lice to fish (Samsing et al. 2015). Thus the effect of exposure on infection rates is not solely through population dynamics at different sites, but also directly acts on the infestation process.

The simple approach to the estimated exchange rate from freshwater input $\left(E_{\mathrm{f}}\right)$ neglects the fact that as fresh water from the river runoff is mixed with saltwater, the volume of the exchange flow out of the fjord may greatly exceed the river flow, easily by as much as a factor of 100 (Hansen 2000). In this study, we did not attempt to calculate an exact exchange rate driven by freshwater input, since it would require salinity observations within the various fjords (Knudsen 1900, as cited by Pickard \& Emery 1990). Such salinity profiles were unavailable for all sites. More importantly, actual mixing within the fjord would depend on tidal energy, variables already incorporated in the other exposure factors through tidal exchange and tidal dispersion. An estimate of estuarine-driven exchange as per Knudsen's relationship would exacerbate the correlations of the variables used in the analysis. Freshwater inflow from land drainage therefore provides an independent variable that pertains to exchange circulation and exposure. One possible issue that we have yet to explore is the seasonality in land run-off. In our analysis, we only used a mean annual estimate, but it is known that winter and summer values are quite different. This, coupled with the temperature effects on salmon lice growth rates, could confound our results somewhat with underestimation of freshwater effects in winter and overestimation in summer.

Despite the simplified physical description of exchange processes, the regression model relating the exposure variables to salmon lice growth rate was highly significant and explained $65 \%$ of the observed variation. Two outliers were observed in the model, viz. 2 data sets (K2010 and K2011) from fjord K (Fig. 5). K2009 did not deviate from the model estimate. It seems that the exposure for fjord $\mathrm{K}$ was somewhat underestimated in the model. Most of the Faroese fjords, as post-glacial features (Elliott \& McLusky 2002), contain a sill at the vicinity of the mouth. Fjord $\mathrm{K}$ is distinct as it is not a sill fjord, with a depth of $130 \mathrm{~m}$ at the mouth slowly decreasing into the fjord. The tidal effect is likely enhanced on fjord $\mathrm{K}$, as it has a less restricted connection to the open sea compared to other fjords. Further, within fjord K, differences in the salmon lice dynamics observed at K2009 and K2010 can be attributed to their setting within the fjord. In fjord $K$, the flow is cyclonic with an inflow on one side of the fjord and a corresponding outflow on the other side. K2009, which is on the outflow side, might thus have had an increased rate of infection of salmon lice copepodids from K2010 on the inflow side, and therefore a higher rate of internally driven outbreak than K2010, and a higher rate of internally driven outbreak than K2011, as no other farms were in the fjord simultaneously in 2011.

While our exposure model provides a relatively good explanation of observed differences in infection rates, it still falls short in that $35 \%$ of the observed variance remains unexplained, and is likely due to other factors such as host density and wind effects. Weather conditions on the Faroe Islands are notoriously variable, and winds are a powerful influence on the conditions on the shelf as well as within the fjords (Hansen 2000). The nature of wind-driven circulation, however, is largely episodic and random. The ever-changing effect of the wind will have major impacts on short-term self-infectiveness of a site, but over the long term, its effect is to contribute to the general background of mixing that is relatively uniform in space. As with land drainage, there is the possibility of seasonal variations that co-vary with temperature-dependent growth rates.

A range of additional factors can alter sea lice composition and infestation, including functional feeds (Jensen et al. 2015), selective breeding (Gharbi et al. 2015), the use of artificial lights (Hevrøy et al. 2003, Oppedal et al. 2011, Aarseth \& Schram 1999) and the physiological status of the fish; for example, salmon 
stressed by osmoregulation have a higher susceptibility to infection by L. salmonis (Dawson et al. 1997).

Tidal dispersion $\left(E_{\mathrm{tp}}\right)$ had a significant effect on the population growth of the salmon lice. It is the only model variable that farmers can influence without too much effort, by relocating the site of the farm. There is, however, a fundamental trade-off to be considered: increasing the exposure of the farm will decrease the level of self-infection, but could also increase the external infection pressure. The exchange of water between sites and the degree of externally derived sea lice is of course highly dependent on the connectivity between sites, a parameter that depends not just on distance, but on circulation patterns. Farms with different rates of self-infection should be managed differently, as lowexposure fjords seem to have a lower threshold of total stocked salmon. Further, at low exposure sites, once the number of sea lice reaches the threshold for treatment, the local environment will also be highly infectious and a single treatment will not be sufficient to ensure that re-infection does not occur.

Overall, our attempt to explain the growth rate of salmon lice from estimations of exposure predictor variables produced a robust model, which was highly significant $(p=0.0073)$. The equation for calculating the combined factor of exposure, although an estimation, is believed to be a reasonable parameter for further use in epidemiological studies on sea lice in salmon farms within the range observed in the statistical model.

\section{CONCLUSIONS}

As stated by Revie et al. (2005, p. 611): 'No single or simple factor is able to account for the variation in the patterns of infection, and factors interact in a complex way'. In this study, we have made an attempt to relate the physical exposure of farming sites with salmon lice population dynamics. The simple fjord systems in the Faroe Islands are well suited to investigate this relationship. The results, although based on simplified proxies, show a significant relationship between infection rate and exposure, with lower rates at high-exposure sites. Our results also indicate that external infestation becomes an increasingly important factor in the most exposed fjords. Knowledge of sea lice and their interactions with the environment is fundamental in the ongoing struggle against the parasites. Characterizing fjords and farms of the Faroe Islands at different exposure levels and how they relate to infection rates is an important step in an eco-friendly direction for combatting the sea lice. The results can be used to aid in the management of the different sites, as well as in decisionmaking processes such as advising on locations that are best suited to mitigate the sea lice problem.

Acknowledgements. We thank Poul Christoffur Thomassen for help and guidance with the statistics. Funding and facilities were provided by Fiskaaling - the Aquaculture Research Station of the Faroes. Sea lice data were provided by the Faroese aquaculture farming companies P/F Bakkafrost, P/F Luna and Marine Harvest Faroes, as well as by the Faroe Marine Research Institute and Landsverk.

\section{LITERATURE CITED}

Á Norði G, Simonsen K, Patursson $\varnothing$ (2016) A method of estimating in situ salmon louse nauplii production at fish farms. Aquacult Environ Interact 8:397-405

Aarseth KA, Schram TA (1999) Wavelength-specific behaviour in Lepeophtheirus salmonis and Calanus finmarchicus to ultraviolet and visible light in laboratory experiments (Crustacea: Copepoda). Mar Ecol Prog Ser 186: 211-217

Adams T, Black K, MacIntyre C, MacIntyre I, Dean R (2012) Connectivity modelling and network analysis of sea lice infection in Loch Fyne, west coast of Scotland. Aquacult Environ Interact 3:51-63

Amundrud TL, Murray AG (2009) Modelling sea lice dispersion under varying environmental forcing in a Scottish sea loch. J Fish Dis 32:27-44

Anderson RM, May RM (1978) Regulation and stability of host-parasite population interactions. J Anim Ecol 47: 219-247

Anderson RM, May RM (1991) Infectious diseases of humans. Oxford University Press, Oxford

* Asplin L, Johnsen IA, Sandvik AD, Albretsen J, Sundfjord V, Aure J, Boxaspen KK (2014) Dispersion of salmon lice in the Hardangerfjord. Mar Biol Res 10:216-225

Brooks KM (2005) The effects of water temperature, salinity, and currents on the survival and distribution of the infective copepodid stage of sea lice (Lepeophtheirus salmonis) originating on Atlantic salmon farms in the Broughton Archipelago of British Columbia, Canada. Rev Fish Sci 13:177-204

Costello MJ (2006) Ecology of sea lice parasitic on farmed and wild fish. Trends Parasitol 22:475-483

* Costello MJ (2009) The global economic cost of sea lice to the salmonid farming industry. J Fish Dis 32:115-118

Davidsen E, Førland E, Madsen H (1994) Orographically enhanced precipitation on the Faroe Islands. Nordic Hydrographical Conference, 2-4 August 1994, Torshavn, p 229-239

Dawson LHJ, Pike AW, Houlihan DF, McVicar AH (1997) Comparison of the susceptibility of sea trout (Salmo trutta L.) and Atlantic salmon (Salmo salar L.) to sea lice (Lepeophtheirus salmonis (Krøyer, 1837)) infections. ICES J Mar Sci 54:1129-1139

FElliott M, McLusky DS (2002) The need for definitions in understanding estuaries. Estuar Coast Shelf Sci 55: 815-827 
Faroese Food and Veterinary Authority (2009) Kunngerð nr. 163. http://logir.fo

Faroese Food and Veterinary Authority (2013) HS mál 13/00854-7. www.hfs.fo

Farvandsvæsenet (2005) Tidevandstabeller 2006 for færøske farvande. Forsvarsministeriets trykkeri, Copenhagen

Frazer LN, Morton A, Krkošek M (2012) Critical thresholds in sea lice epidemics: evidence, sensitivity and subcritical estimation. Proc R Soc Lond B Biol Sci 279: 1950-1958

* Gaard E, á Norði G, Simonsen K (2011) Environmental effects on phytoplankton production in a Northeast Atlantic fjord, Faroe Islands. J Plankton Res 33:947-959

Geyer WR, Signell RP (1992) A reassessment of the role of tidal dispersion in estuaries and bays. Estuaries 15: 97-108

Gharbi K, Matthews L, Bron J, Roberts R, Tinch A, Stear M (2015) The control of sea lice in Atlantic salmon by selective breeding. J R Soc Interface 12:0574

*Hansen B (2000) Havið. Føroya skúlabókagrunnur, Tórshavn

Hansen B, Østerhus S (2000) North Atlantic-Nordic Seas exchanges. Prog Oceanogr 45:109-208

*Heuch PA, Nordhagen JR, Schram TA (2000) Egg production in the salmon louse [Lepeophtheirus salmonis (Krøyer)] in relation to origin and water temperature. Aquacult Res 31:805-814

*Heuch PA, Olsen RS, Malkenes R, Revie CW and others (2009) Temporal and spatial variations in lice numbers on salmon farms in the Hardangerfjord 2004-06. J Fish Dis 32:89-100

*Hevrøy EM, Boxaspen K, Oppedal F, Taranger GL, Holm JC (2003) The effect of artificial light treatment and depth on the infestation of the sea louse Lepeophtheirus salmonis on Atlantic salmon (Salmo salar L.) culture. Aquaculture 220:1-14

Jackson D, Minchin D (1992) Aspects of the reproductive output of two caligid copepod species parasitic on cultivated salmon. Invertebr Reprod Dev 22:87-90

Jansen PA, Kristoffersen AB, Viljugrein $H$, Jimenez D, Aldrin M, Stien A (2012) Sea lice as a density-dependent constraint to salmonid farming. Proc R Soc B 279: 2330-2338

Jaworski A, Holm JC (1992) Distribution and structure of the population of sea lice Lepeoptheirus salmonis Krøyer, on Atlantic salmon Salmo salar L. under typical rearing conditions. Aquacult Fish Manag 23:577-589

Jensen LB, Provan F, Larssen E, Bron JE, Obach A (2015) Reducing sea lice (Lepeophtheirus salmonis) infestation of farmed Atlantic salmon (Salmo salar L.) through functional feeds. Aquacult Nutr 21:983-993

Jimenez D, Heuch PA, Brun E (2011) Evaluering av lusetellingsprotokoll og bioassay for nedsatt følsomhet mot lakselusmidler. Veterinærinst Rapportser 9-2011, Norwegian Veterinary Institute, Oslo

Johnsen IA, Fiksen Ø, Sandvik AD, Asplin LC (2014) Vertical salmon lice behaviour as a response to environmental conditions and its influence on the regional dispersion in a fjord system. Aquacult Environ Interact 5:127-141

Johnsen IA, Asplin LC, Sandvik AD, Serra-Llinares RM (2016) Salmon lice dispersion in a northern Norwegian fjord system and the impact of vertical movements. Aquacult Environ Interact 8:99-116

Knudsen M (1900) Ein hydrographischer Lehrsatz. Ann Hydrogr Mar Meteorol 28:316-320
Krkošek M, Lewis MA, Volpe JP (2005) Transmission dynamics of parasitic sea lice from farm to wild salmon. Proc R Soc Lond B Biol Sci 272:689-696

Krkošek M, Bateman A, Proboszcz S, Orr C (2010) Dynamics of outbreak and control of salmon lice on two salmon farms in the Broughton Archipelago, British Columbia. Aquacult Environ Interact 1:137-146

* Larsen KMH, Hansen B, Svendsen H (2008) Faroe shelf water. Cont Shelf Res 28:1754-1768

* Lees F, Gettinby G, Revie CW (2008) Changes in epidemiological patterns of sea lice infestation on farmed Atlantic salmon, Salmo salar L., in Scotland between 1996 and 2006. J Fish Dis 31:259-268

Mikhailov VN (1997) Gidrologicheskie prostessy V ust'yakhrek (Hydrological processes in river mouths). GEOS, Moscow

Nguyen AD, Savenije HHG, van der Wegen M, Roelvink D (2008) New analytical equation for dispersion in estuaries with a distinct ebb-flood channel system. Estuar Coast Shelf Sci 79:7-16

\%oppedal F, Dempster T, Stien LH (2011) Environmental drivers of Atlantic salmon behaviour in sea-cages. Rev Aquacult 311:1-18

Pickard GL, Emery WJ (1990) Descriptive physical oceanography: an introduction, 5th enlarged edn. Pergamon Press, New York, NY

Pike AW, Wadsworth SL (1999) Sealice on salmonids: their biology and control. In: Baker JR, Muller R, Rollinson D (eds) Advances in parasitology 44. Academic Press, London, p 234-337

Pritchard DW (1967) What is an estuary: physical viewpoint. In: Lauff GH (ed) Estuaries. American Association for the Advancement of Science, Washington, DC, p 3-5

R Core Team (2013) R: a language and environment for statistical computing. R Foundation for Statistical Computing, Vienna. www.r-project.org

Revie CW, Gettinby G, Treasurer JW, Wallace C (2003) Identifying epidemiological factors affecting sea lice Lepeophtheirus salmonis abundance on Scottish salmon farms using general linear models. Dis Aquat Org 57: 85-95

Revie CW, Robbins C, Gettinby G, Kelly L, Treasurer JW (2005) A mathematical model of the growth of sea lice, Lepeophtheirus salmonis, populations on farmed Atlantic salmon, Salmo salar L., in Scotland and its use in the assessment of treatment strategies. J Fish Dis 28: $603-613$

* Salama NKG, Collins CM, Fraser JG, Dunn J, Pert CC, Murray AG, Rabe B (2013) Development and assessment of a biophysical dispersal model for sea lice. J Fish Dis 36: 323-337

Samsing F, Oppedal F, Johanson D, Bui S, Dempster T (2014) High host densities dilute sea lice Lepeophtheirus salmonis loads on individual Atlantic salmon, but do not reduce lice infection success. Aquacult Environ Interact 6:81-89

Samsing F, Solstorm D, Oppedal F, Solstrom F, Dempster T (2015) Gone with the flow: current velocities mediate parasitic infestation of an aquatic host. Int J Parasitol 45: 559-565

Shchepetkin F, McWilliams JC (2005) The regional oceanic modeling system (ROMS): a split-explicit, free-surface, topography-following-coordinate oceanic model. Ocean Model 9:347-404 
Simonsen K, Niclasen BA (2011) On the energy potential in the tidal streams of The Faroe Islands. Tech Rep NVDrit 2011:01. University of the Faroe Islands, Tórshavn

Tucker CS, Sommerville C, Wootten R (2002) Does size really matter? Effects of fish surface area on the settlement and initial survival of Lepeophtheirus salmonis, an ectoparasite of Atlantic salmon Salmo salar. Dis Aquat Org 49:145-152

Tully O (1992) Predicting infestation parameters and

Editorial responsibility: Kenneth Black,

Oban, UK impacts of caligid copepods in wild and cultured fish populations. Invertebr Reprod Dev 22:91-102

Tully O, Nolan DT (2002) A review of population biology and host-parasite interactions of the sea lice Lepeophtheirus salmonis (Copepoda: Caligidae). Parasitology 124: 165-182

* Visser AW, Bowman MJ (1991) Lagrangian tidal stress and basin-wide residual eddy dynamics in wide coastal sea straits. Geophys Astrophys Fluid Dyn 59:113-145

Submitted: July 18, 2016; Accepted: November 11, 2016 Proofs received from author(s): January 15, 2017 